\title{
Literaturbericht
}

\section{Richard von Weizsäckers Parteienkritik revisited}

„Die Parteien wirken bei der politischen Willensbildung des Volkes mit.“ So ist in Artikel 21 Absatz 1 des Grundgesetzes zu lesen. Obwohl Parteien schon früh als ein Grundpfeiler der demokratischen Ordnung der Bundesrepublik Deutschland galten, haben sie ihren Einfluss im Laufe der Zeit stark ausweiten können. Diese zentrale Stellung der Parteien in der Bundesrepublik findet nicht zuletzt in der Bezeichnung „Parteiendemokratie“ prominent Ausdruck. Einem wertneutralen Verständnis - das die bedeutende Rolle der Parteien bei der politischen Willensbildung und Entscheidungsfindung hervorhebt - steht dabei eine parteienkritische Lesart gegenüber.

Vor mehr als 20 Jahren äußerte der damalige Bundespräsident Richard von Weizsäcker in einem Gesprächsband denn auch teils massive Kritik an den deutschen Parteien. Mit deutlichen Worten wies er auf den seiner Meinung nach damals beherrschenden Einfluss der Parteien in Staat, Politik und Gesellschaft hin - einen Einfluss, den die Verfassungsväter und -mütter in den Augen von Weizsäckers so nicht beabsichtigt hatten. Damit stieß der Bundespräsident eine vielbeachtete Diskussion in den Medien, der Wissenschaft und natürlich der Politik und den Parteien selbst an.

Doch wo stehen die deutschen Parteien heute? Wie ist es um deren Einfluss auf Politik, Staat und Gesellschaft bestellt? Nach zwei Jahrzehnten ist es an der Zeit, die Kritik von Weizsäckers wieder aufzunehmen und die damalige Diagnose erneut auf den Prüfstand zu stellen. Aus diesem Grund hat die Zeitschrift für Politikwissenschaft für Ihre Rubrik „Literaturbericht“ Autoren, die bereits im Jahr 1992 Stellung zu den Thesen Richard von Weizsäckers bezogen hatten, gebeten, dies erneut zu tun. Mit Jürgen Rüttgers, Wolfgang Thierse und Claus Leggewie konnten hierfür namhafte Protagonisten aus Politik und Wissenschaft gewonnen werden. 